\title{
Multilevel Inverters for Electric Vehicle Applications
}

\author{
Leon M. Tolbert, Fang Z. Peng \\ Oak Ridge National Laboratory* \\ P.O. Box 2009 \\ Oak Ridge, TN 37831-8038 \\ Tel: (423) 576-6206 \\ FAX: (423) 241-6124 \\ E-mail: tolbertlm@ornl.gov \\ E-mail: pengfz@ornl.gov
}

\author{
Thomas G. Habetler \\ Georgia Institute of Technology \\ School of Electrical and Computer Engineering \\ Atlanta, GA 30332-0250 \\ Tel: (404) 894-9829 \\ FAX: (404) 894-9171 \\ E-mail: tom.habetler@ece.gatech.edu
}

\begin{abstract}
This paper presents multilevel inverters as an application for all-electric vehicle (EV) and hybrid-electric vehicle (HEV) motor drives. Diode-clamped inverters and cascaded H-bridge inverters, (1) can generate near-sinusoidal voltages with only fundamental frequency switching; (2) have almost no electromagnetic interference (EMI) and commonmode voltage; and (3) make an EV more accessible/safer and open wiring possible for most of an EV's power system. This paper explores the benefits and discusses control schemes of the cascade inverter for use as an EV motor drive or a parallel HEV drive and the diode-clamped inverter as a series HEV motor drive. Analytical, simulated, and experimental results show the superiority of these multilevel inverters for this new niche.
\end{abstract}

\section{BACKGROUND}

The development of electric and hybrid-electric vehicles will offer many new opportunities and challenges to the power electronics industry, especially in the development of the main traction motor drive [1]. Many current and future designs will incorporate the use of induction motors as the primary source for traction in electric vehicles.

Designs for heavy duty trucks and many military combat vehicles that have large electric drives will require advanced power electronic inverters to meet the high power demands (>250 kW) required of them. Development of electric drive trains for these large vehicles will result in increased fuel efficiency, lower emissions, and likely better vehicle performance (acceleration and braking).

Multilevel inverters are uniquely suited for this application because of the high VA ratings possible with these inverters $[2,3]$. Where generated ac voltage is available such as from an alternator or ac generator, a back-to-back diode-clamped converter can convert this source to variable frequency ac voltage for the driven motor. For electric vehicles (EVs), a cascaded $\mathrm{H}$-bridges inverter can be used to drive the traction

Prepared by the Oak Ridge National Laboratory, Oak Ridge, Tennessee 378318038, managed by Lockheed Martin Energy Research, Corp. for the U.S. Department of Energy under contract DE-AC05-96OR22464. A contractor of the U.S. Government has authored the submitted manuscript. Accordingly, the U.S. Government retains a nonexclusive, royalty-free license to publish or reproduce the published form of this contribution, or allow others to do so, for U.S. Government purposes. motor from a set of batteries or fuel cells.

Some traditional 2-level high-frequency pulse width modulation (PWM) inverters for automotive drives can have problems associated with their high voltage change rates $(\mathrm{dV} / \mathrm{dt})$, which produces a common mode voltage across the motor windings. High frequency switching can exacerbate the problem because of the numerous times this common mode voltage is impressed upon the motor each cycle. PWM controlled inverters also require a greater amount of heat removal because of the additional switching losses [4-6].

Multilevel inverters solve these problems because their individual devices have a much lower $\mathrm{dV} / \mathrm{dt}$ per switching, and they operate at high efficiencies because they can switch at a lower frequency than PWM-controlled inverters.

\section{MULTILEVEL INVERTERS}

The multilevel voltage source inverters' unique structure allows them to reach high voltages and power levels without the use of transformers. They are specially suited to high voltage vehicle drives where low output voltage total harmonic distortion (THD) and electromagnetic interference (EMI) are needed. The general function of the multilevel inverter is to synthesize a desired voltage from several levels of dc voltages. For this reason, multilevel inverters can easily provide the high power required of a large EV or HEV drive.

As the number of levels increases, the synthesized output waveform has more steps, which produces a staircase wave that approaches the desired waveform. Also, as more steps are added to the waveform, the harmonic distortion of the output wave decreases, approaching zero as the number of levels increases. As the number of levels increases, the voltage that can be spanned by connecting devices in series also increases. The structure of the multilevel inverter is such that no voltage sharing problems are encountered by the active devices [7].

Using multilevel inverters as drives for automotive electric motors is a much different application than for the utility applications for which they were originally developed [7-9]. Only reactive power flows between the converter and the system in static var compensation, whereas the converter 


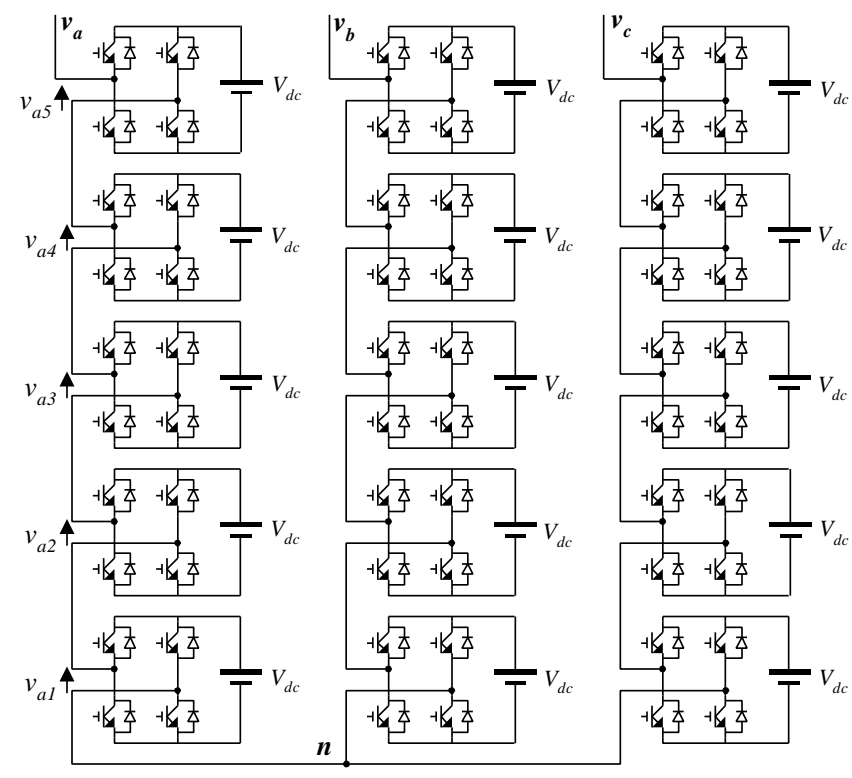

Fig. 1. 11-level wye-configured cascaded inverter.

must handle bidirectional real power flow in the case of motor drives.

Three, four, and five level rectifier-inverter drive systems which have used some form of multilevel PWM as a means to control the switching of the rectifier and inverter sections have been investigated in the literature [11-15]. Multilevel

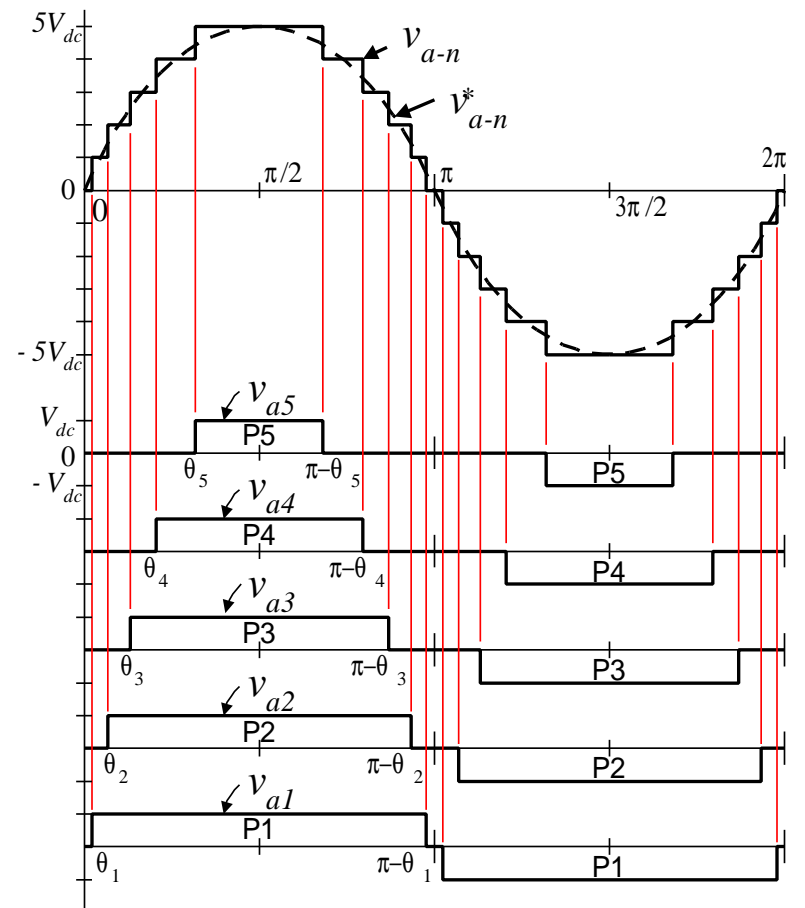

(a)
PWM has lower $\mathrm{dV} / \mathrm{dt}$ than that experienced in some twolevel PWM drives because switching is between several smaller voltage levels. However, switching losses and voltage total harmonic distortion (THD) are still relatively high for these proposed schemes; the output voltage THD was reported to be $19.7 \%$ for a four-level PWM inverter [14].

This paper proposes a multilevel inverter control scheme where devices are switched only at the fundamental frequency and the inverter output line voltage THD is generally less than 5 percent without the use of any filtering components.

\section{CASCADEd H-Bridges MultileVEl INVERTER}

A cascade multilevel inverter consists of a series of $\mathrm{H}$ bridge (single-phase full bridge) inverter units in each of its three phases. Fig. 1 shows an 11-level phase-neutral (21level line-line) cascade inverter connected in a wyeconfiguration. Each H-bridge unit has its own dc source, which for an electric vehicle would be a battery unit. This cascade inverter makes EVs more accessible/safer and open wiring possible for most of an EV's power system because each low voltage $(<50 \mathrm{~V})$ battery is isolated through switching devices. When switching devices are in an offstate, the leakage current is far less than the safety limit (10 $\mathrm{mA}$ ), which makes access possible to any point of the system.

Fig. 2 shows the waveforms of the 11-level cascade
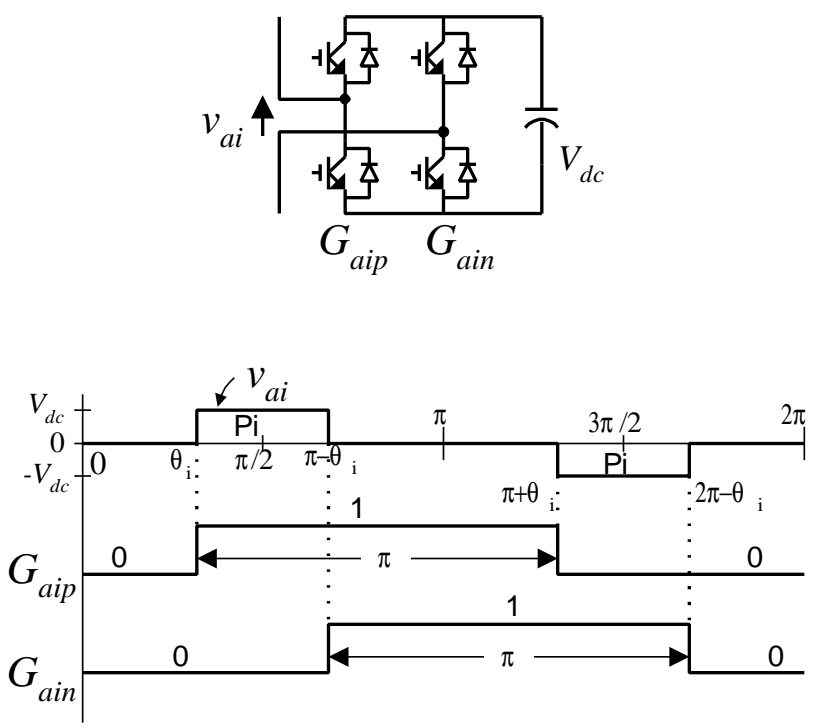

$G_{\text {aip }}, G_{\text {ain }}=$ "0": Lower device on; "1": Upper device on.

(b)

Fig. 2. Waveforms and switching method of the 11-level cascade inverter. 


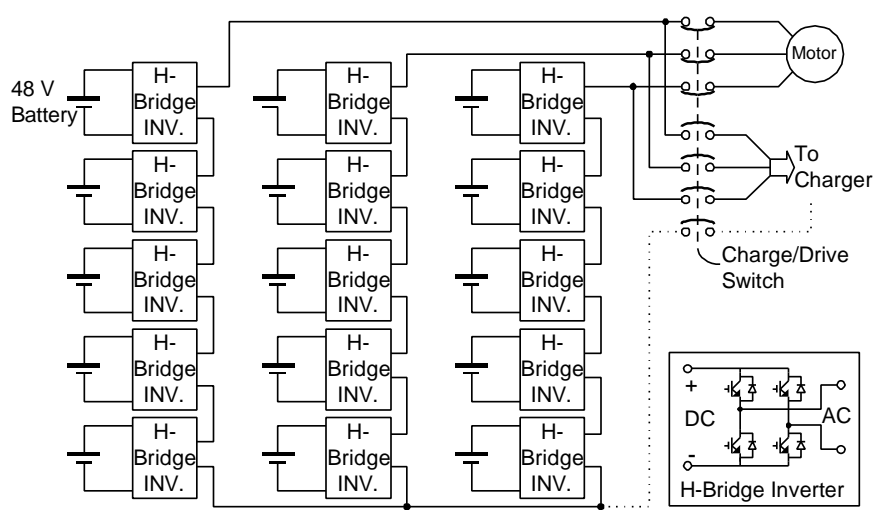

Fig. 3. System configuration of an EV motor drive using a cascade inverter.

inverter. The output voltage of the inverter is almost sinusoidal, and it has less than 5\% THD with each of the $\mathrm{H}$-bridges switching only at fundamental frequency. Each $\mathrm{H}$ bridge unit generates a quasi-square waveform by phaseshifting its positive and negative phase legs' switching timings. Fig. 2(b) shows the switching timings to generate a quasi-square waveform. Note that each switching device always conducts for $180^{\circ}$ (or $1 / 2$ cycle) regardless of the pulse width of the quasi-square wave. This switching method makes all of the switching devices' current stress equal.

The system configuration of an EV motor drive using the cascade inverter is shown in Fig. 3. In the motoring mode, power flows from the batteries through the cascade inverters to the motor. In the charging mode, the cascade converters act as rectifiers, and power flows from the charger (ac source) to the batteries. The cascade converters can also act as rectifiers to help recover the kinetic energy of the vehicle if regenerative braking is used. The cascade inverter can also be used in parallel HEV configurations.

From Fig. 2, note that the duty cycle for each of the voltage levels is different. If this same pattern of duty cycles is used on a motor drive continuously, then the level 1 battery is cycled on for a much longer duration than the level 5 battery. This means that the level 1 battery will discharge much sooner than the level 5 battery. However, by using a switching pattern swapping scheme among the various levels every $1 / 2$ cycle as shown in Fig. 4 , all batteries will be equally used (discharged) or charged.

The combination of the $180^{\circ}$ conducting method (Fig. 2(b)) and the pattern-swapping scheme (Fig. 4) make the cascade inverter's voltage and current stresses the same and battery voltage balanced. Identical H-bridge inverter units can be utilized, thus improving modularity and manufacturability and greatly reducing production costs.

Fig. 5 shows experimental waveforms of an 11-level battery-fed cascade inverter prototype driving an induction motor at $50 \%$ and $80 \%$ rated speed using the aforementioned fundamental frequency switching scheme. As can be seen from the waveforms, both the voltage and current are almost sinusoidal. Electromagnetic interference (EMI) and common-mode voltage are also much less than what would result from a PWM inverter because of the inherently low $\mathrm{dV} / \mathrm{dt}$ (21 times less than a two-level PWM drive) and sinusoidal voltage output.

In summary, the main advantages of using the cascade inverter in an electric vehicle include: (1) It makes EVs more accessible/safer and open wiring possible for most of

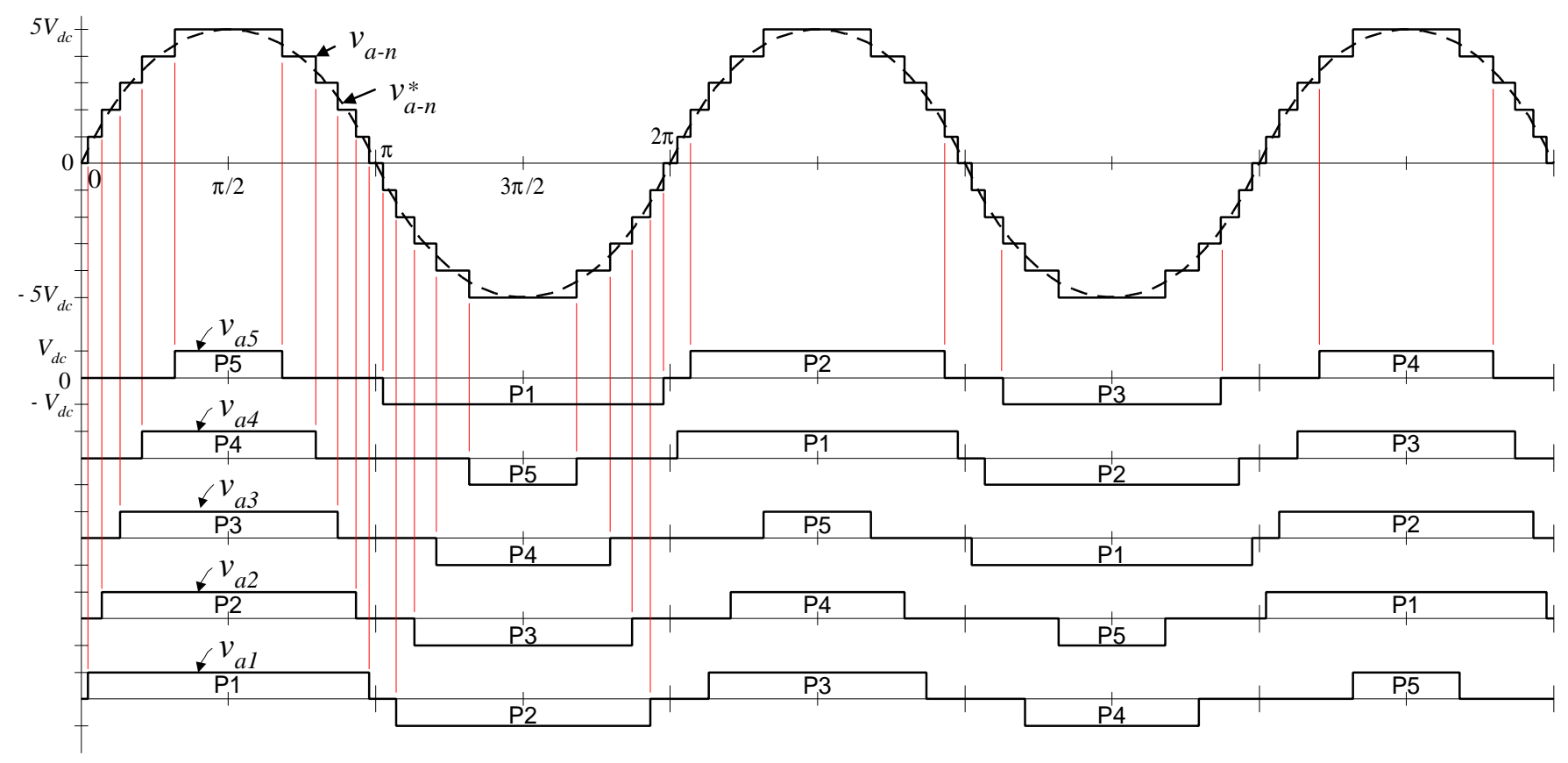

Fig. 4. Switching pattern swapping of the 11-level cascade inverter for balancing battery charge. 


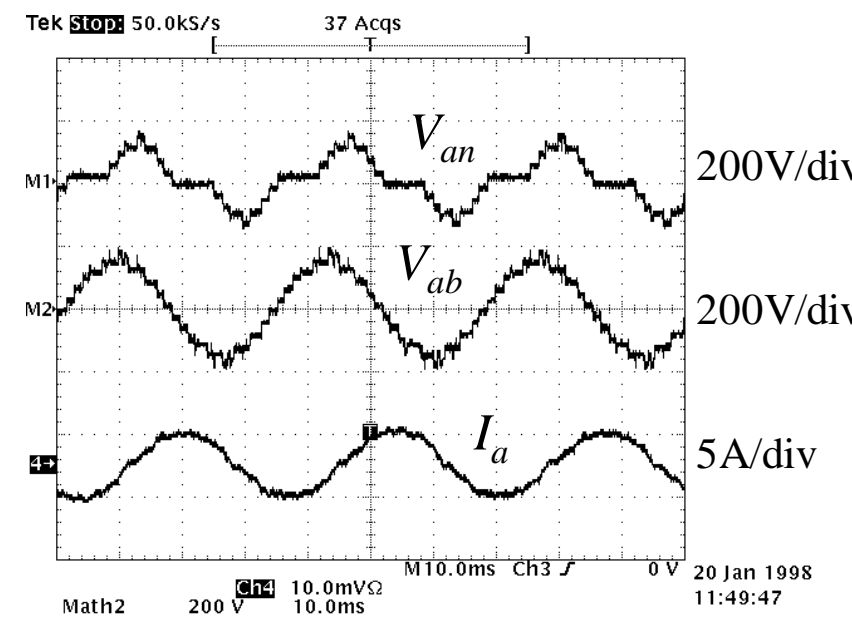

(a)

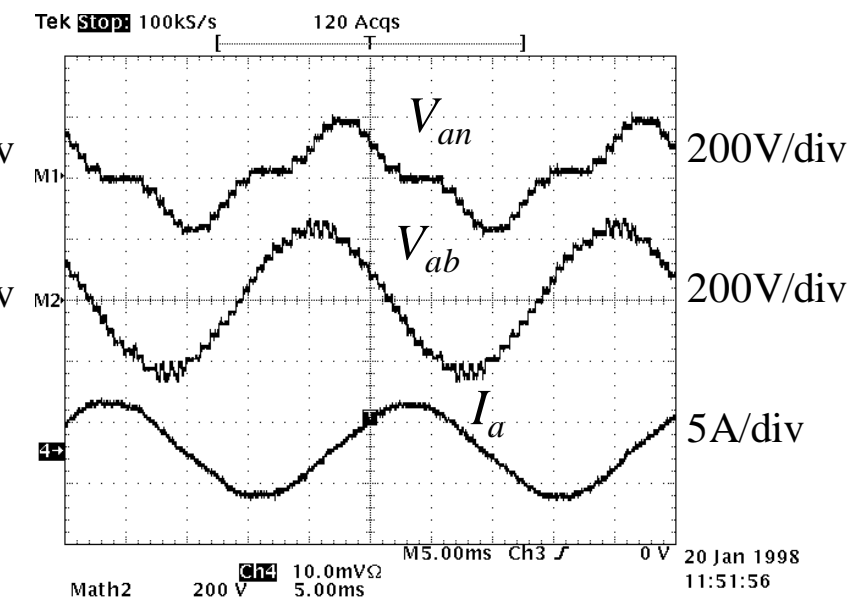

(b)

Fig. 5. Experimental waveforms of a battery-fed cascade inverter prototype driving an induction motor at (a) $50 \%$ rated speed and (b) $80 \%$ rated speed.

an EV's power system. (2) Traditional $230 \mathrm{~V}$ or $460 \mathrm{~V}$ motors can be used, thus higher efficiency is expected as compared to low voltage motors. (3) No EMI problem or common-mode voltage/current problem exists. (4) Low voltage switching devices can be used. (5) No charge unbalance problem exists in both charge mode and drive mode.

\section{BACK-TO-BACK DIODE-CLAMPED CONVERTER DRIVE}

Development of a hybrid electric drive train for heavy duty trucks and military vehicles will result in increased fuel efficiency, lower emissions, and likely better vehicle performance (acceleration and braking). While cascade inverters are ideal for an all-electric vehicle that has many separate dc sources (batteries) available for the individual $\mathrm{H}$ bridges, these inverters are not an option for series hybridelectric vehicles because cascade inverters cannot be easily

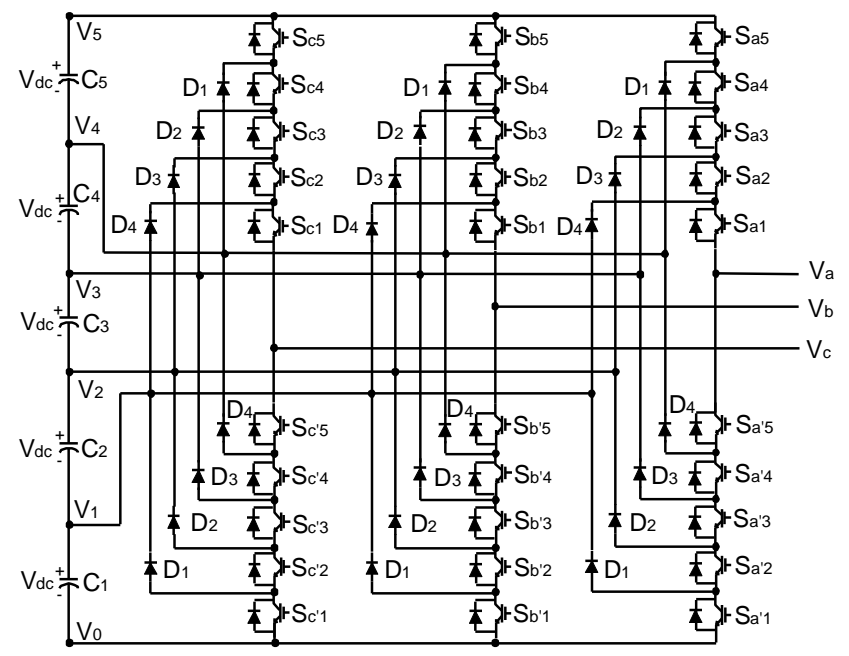

Fig. 6. Three-phase 6-level diode-clamped inverter structure. connected back-to-back. For series-configured HEVs where an onboard combustion engine generates ac power via an alternator or generator, a multilevel back-to-back diodeclamped converter drive can best interface with the source of ac power and yet still easily meet the high power and/or high voltage requirements of the traction motor.

The diode-clamped converter is the most popular structure proposed as a transformerless voltage source inverter, and it is based on the neutral point converter [10]. Each of the three phases of the inverter shares a common dc bus that is divided into smaller equal levels of dc voltage by either batteries or capacitors, as shown in Fig. 6. The output ac voltage waveform is constructed by connecting the three lines to differing levels of dc voltage such that a staircase waveform is generated. As with the cascade inverter, almost sinusoidal output voltage can be achieved with only individual device fundamental frequency switching.

Table I lists the voltage output levels possible for one phase of a 6-level diode-clamped inverter using the negative dc rail $V_{0}$ as a reference voltage. State condition 1 means the switch is on, and 0 means the switch is off. Note that each active device is only switched once per cycle. Each phase has five complementary switch pairs such that turning on one of the switches of the pair requires that the other switch be turned off. The complementary switch pairs for phase leg $a$ are $\left(S_{a l}\right.$, $\left.S_{a^{\prime} 1}\right),\left(S_{a 2}, S_{a^{\prime} 2}\right),\left(S_{a 3}, S_{a^{\prime} 3}\right),\left(S_{a 4}, S_{a^{\prime} 4}\right)$, and $\left(S_{a 5}, S_{a^{\prime} 5}\right)$.

TABLE I

Diode-clamp 6-level inverter voltage levels and corresponding switch states

\begin{tabular}{|l|c|c|c|c|c|c|c|c|c|c|}
\hline Output & \multicolumn{10}{|c|}{ Switch State } \\
\cline { 2 - 12 } \multicolumn{1}{c|}{$V_{a}$} & $S_{a 5}$ & $S_{a 4}$ & $S_{a 3}$ & $S_{a 2}$ & $S_{a 1}$ & $S_{a^{\prime} 5}$ & $S_{a^{\prime} 4}$ & $S_{a^{\prime} 3}$ & $S_{a^{\prime} 2}$ & $S_{a^{\prime} 1}$ \\
\hline$V_{5}=5 V_{d c}$ & 1 & 1 & 1 & 1 & 1 & 0 & 0 & 0 & 0 & 0 \\
\hline$V_{4}=4 V_{d c}$ & 0 & 1 & 1 & 1 & 1 & 1 & 0 & 0 & 0 & 0 \\
\hline$V_{3}=3 V_{d c}$ & 0 & 0 & 1 & 1 & 1 & 1 & 1 & 0 & 0 & 0 \\
\hline$V_{2}=2 V_{d c}$ & 0 & 0 & 0 & 1 & 1 & 1 & 1 & 1 & 0 & 0 \\
\hline$V_{I}=V_{d c}$ & 0 & 0 & 0 & 0 & 1 & 1 & 1 & 1 & 1 & 0 \\
\hline$V_{0}=0$ & 0 & 0 & 0 & 0 & 0 & 1 & 1 & 1 & 1 & 1 \\
\hline
\end{tabular}




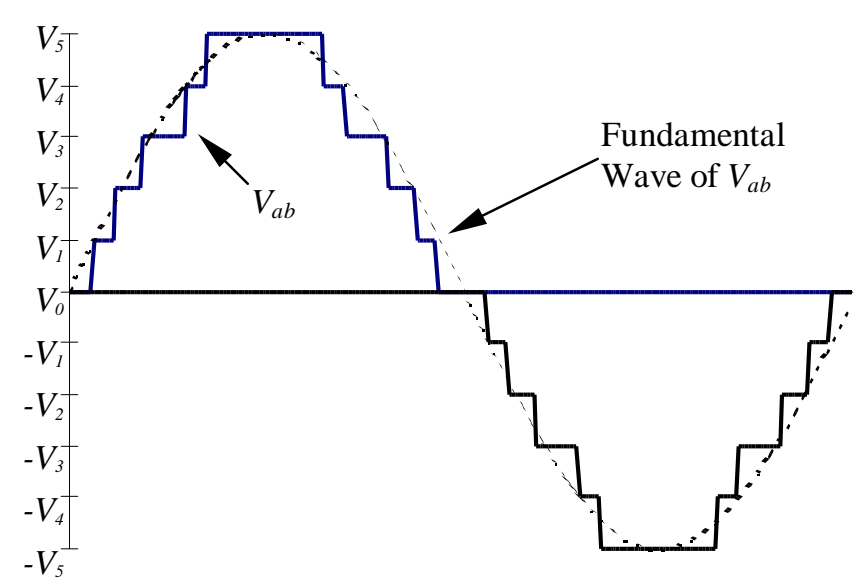

Fig. 7. Voltage waveform for a diode-clamped inverter.

Fig. 7 shows phase and line voltage waveforms for one phase of a 6-level inverter. The line-line voltage $V_{a b}$ consists of a phase-leg $a$ voltage and a phase-leg $b$ voltage. The resulting line-line voltage is an 11-level staircase waveform. This means that an $m$-level diode-clamped inverter has an $m$ level output phase voltage and a (2m-1)-level output line voltage [9].

Although each active switching device is only required to block a voltage level of $V_{d c}$, the clamping diodes require different voltage ratings for reverse voltage blocking. Using phase $a$ of Fig. 6 as an example, when the lower switches $S_{a^{\prime} 1}$ through $S_{a^{\prime} 4}$ are turned on, $D_{4}$ must block four voltage levels, or $4 V_{d c}$. Similarly, $D_{3}$ must block $3 V_{d c}, D_{2}$ must block $2 V_{d c}$, and $D_{l}$ must block $V_{d c}[7]$.

Hybrid-electric vehicles generally have an ac voltage source from an alternator or combustion-engine generator. A rectifier converts this ac voltage to dc for the electric energy storage devices on board - batteries or ultracapacitors. An inverter converts the dc voltage to variable voltage variable frequency ac in order to drive the main traction motor. The system configuration of a series HEV system with two diode-clamped inverters connected back-to-back and sharing a common dc bus is shown in Fig. 8.

By monitoring the voltages of each of the dc link levels, composed of either batteries or ultracapacitors, minor adjustments can be made to either the inverter or the rectifier switching angles. This will transfer a net charge into or out of a particular capacitor or battery unit to adjust the voltage level or state of charge. This enables control of each of the individual voltage levels such that they remain equal, and they will each be charged or discharged equally.

The multilevel converter on the right-hand side of Fig. 8 can act as an inverter in drive mode when energy is being sent to the motor that drives the wheels and as a rectifier during regenerative braking or during charge mode when the vehicle is plugged into an external ac source. Fig. 8

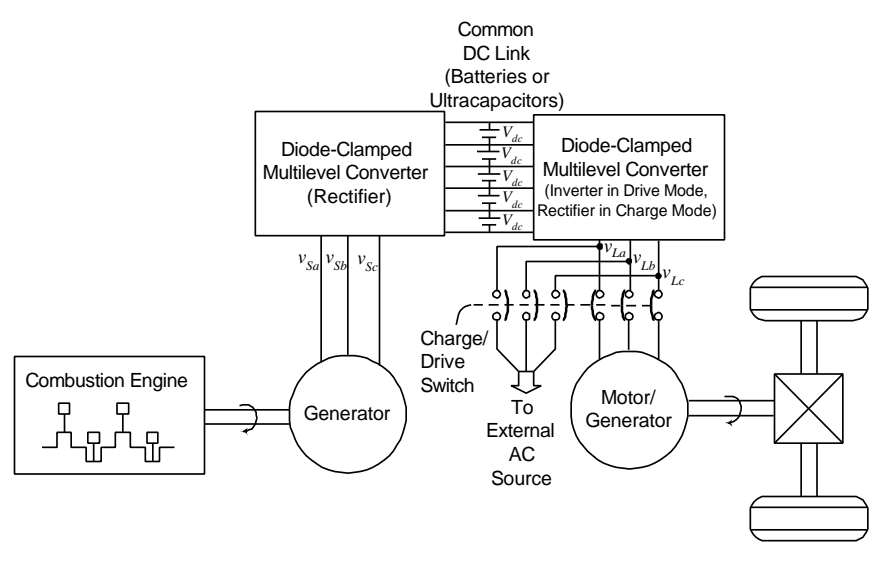

Fig. 8. Series HEV system configuration with back-to-back diode-clamped

represents just one of the many $\mathrm{HEV}$ configurations in which multilevel converters could be applied.

A 6-level back-to-back $10 \mathrm{~kW}$ diode-clamped converter prototype that was designed to operate from a three-phase voltage source of $208 \mathrm{~V}$ line-line has been built and experimentally tested as an adjustable speed drive (ASD) for an induction motor load. Fig. 9 shows the source voltage, $V_{S a b}$; the source current, $I_{S a}$, drawn by the converter; the inverter output load voltage, $V_{L a b}$; and the load current, $I_{L a}$, drawn by a $5 \mathrm{hp}$ induction motor. The multilevel diodeclamped rectifier drew a source current that had a THD of $3 \%$ and could be controlled such that the input power factor was 1.0. The output voltage at the motor terminals had a THD that varied between $4.5 \%$ and $5.3 \%$, and the converter output current had a THD of $3 \%$.

Additionally, the experiment shows that the output line voltage $\mathrm{dV} / \mathrm{dt}$ is reduced by 11 times with the 6-level converter as compared to a traditional 2-level PWM drive. The dramatic reduction in $\mathrm{dV} / \mathrm{dt}$ by one order in magnitude and two orders in repetition (switching frequency) can prevent motor windings and bearings from failure. This 11step staircase output voltage waveform approaches a sinewave, thus having no common-mode voltage and no voltage surge to the motor windings.

Power at the input and the output of the $10 \mathrm{~kW}$ multilevel ASD prototype was measured at several different operating points from no load up to full load. Efficiency of the multilevel converter, which actually consists of two multilevel inverters connected back to back, was then calculated from the following equation:

$$
\text { Efficiency }=\frac{\text { Power Out }}{\text { Power In (including Control Power) }} \text {, }
$$

where Power In was measured at the input to the ac-dc converter, Power Out was measured at the output of the dcac inverter, and Control Power was measured to be $25 \mathrm{~W}$. 


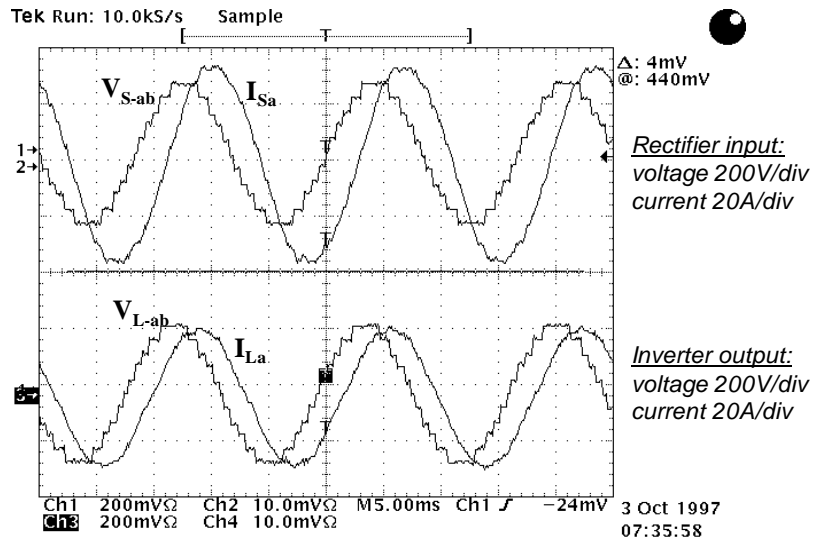

Fig. 9. Experimental voltage and current waveforms at the input and output of the diode-clamped converter prototype.

Fig. 10 shows a graph comparing the efficiency of the back-to-back multilevel converter to a typical industry PWM inverter (operating with a carrier frequency of $3 \mathrm{kHz}$ ) as a function of their fraction of rated output power. The multilevel converter has an efficiency greater than or equal to $96 \%$ for loads greater than $10 \%$ rated power, whereas the PWM inverter did not achieve $90 \%$ efficiency until it was loaded to greater than $30 \%$ rated power. The multilevel converter had an efficiency greater than $98 \%$ for loads greater than $40 \%$ rated power, but the PWM inverter had a maximum efficiency of $95.6 \%$ which was achieved at a loading factor of $95 \%$. The efficiency for a single multilevel inverter is greater than $99 \%$ over most of its operating range.

\section{CONCLUSIONS}

A multilevel cascaded inverter has been proposed for use in electric vehicles. It makes EVs more accessible/safer and open wiring possible for most of an EV's power system because each low voltage $(<50 \mathrm{~V})$ battery is isolated through switching devices. A multilevel diode-clamped back-to-back converter has been proposed for use in large automotive hybrid-electric drives for heavy-duty trucks and military vehicles. Simulation and experimental results have shown that with a control strategy that operates the switches at fundamental frequency, these converters have low output voltage THD and high efficiency.

In summary, the main advantages of using multilevel converters for the main traction drive in electric vehicles include:

1. They are suitable for large VA-rated motor drives, and traditional $230 \mathrm{~V}$ or $460 \mathrm{~V}$ motors can be used

2. Higher efficiency is expected for these multilevel converter systems because higher voltages can be utilized and the switching frequency of the devices is at a minimum.

3. Low voltage switching devices can be used.

4. No EMI problem or common-mode voltage/current problem exists.

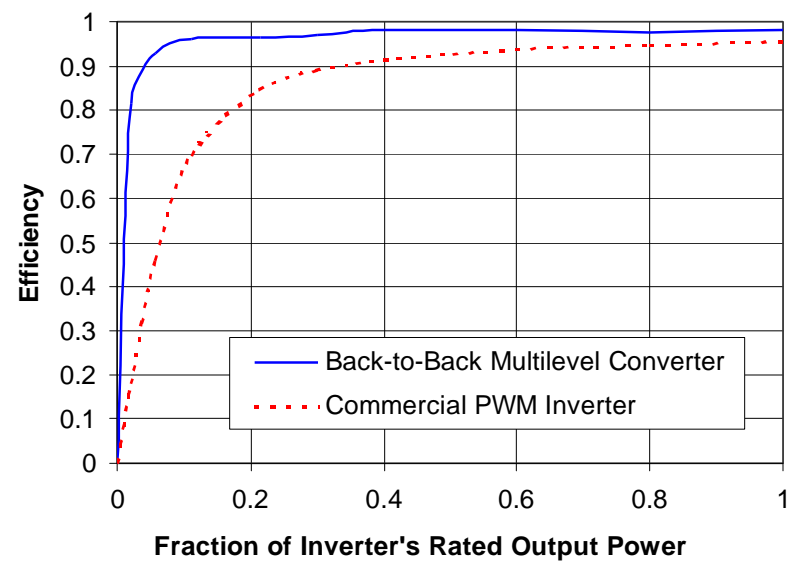

Fig. 10. Plot of back-to-back diode-clamped converter's and two-level PWM inverter's efficiency as a function of rated output power.

5. No charge unbalance problem results from either charge mode or drive mode.

\section{REFERENCES}

[1] J. M. Miller, A. R. Gale, "Hybird-electric vehicle success will depend on low cost, efficient power electronics systems," Power Conversion \& Intelligent Motion (PCIM), Nov. 1997, pp. 22-38.

[2] L. M. Tolbert, F. Z. Peng, "Multilevel inverters for large automotive drives," All Electric Combat Vehicle Second International Conference, June 8-12, 1997, Dearborn, Michigan, vol. 2, pp. 209-214.

[3] L. M. Tolbert, F. Z. Peng, "Multilevel converters for large electric drives," IEEE Applied Power Electronics Conference, 1998, pp. 530-536.

[4] S. Bell, J. Sung, "Will your motor insulation survive a new adjustable frequency drive?", IEEE Trans. Industry Applications, vol. 33, no. 5, Sep. 1997, pp. 1307-1311.

[5] J. Erdman, R. Kerkman, D. Schlegel, G. Skibinski, "Effect of PWM inverters on AC motor bearing currents and shaft voltages," IEEE Trans. Industry Applications, vol. 32, no. 2, Mar. 1996, pp. 250-259.

[6] A. H. Bonnett, "A comparison between insulation systems available for PWM-Inverter-Fed Motors,” IEEE Trans. Industry Applications, vol. 33, no. 5, Sep. 1997, pp. 1331-1341.

[7] J. S. Lai, F. Z. Peng, "Multilevel converters - a new breed of power converters," IEEE Trans. Industry Applications, vol. 32, no. 3, May 1996, pp. 509-517.

[8] F. Z. Peng, J. S. Lai, J. McKeever, J. VanCoevering, "A multilevel voltage-source converter system with balanced dc voltages," Power Electronics Specialists Conference, 1995, pp. 1144-1150.

[9] J. S. Lai, F. Z. Peng, "Power converter options for power system compatible mass transit systems," PCIM/Power Quality and Mass Transit Sys. Compatibility Conf., 1994, Dallas, Texas, pp. 285-294.

[10]A. Nabae, I. Takahashi, H. Akagi, "A new neutral-point-clamped PWM inverter," IEEE Trans. Industry Applications, vol. 17, no. 5, Sept. 1981, pp. 518-523.

[11]J. K. Steinke, "Control strategy for a three phase ac traction drive with three level GTO PWM inverter," PESC, 1988, pp. 431-438.

[12]M. Klabunde, Y. Zhao, T.A. Lipo, "Current control of a 3-level rectifier/inverter drive system," Conf. Rec. of IEEE IAS Annual Meeting, 1994, pp. 2348-2356.

[13] J. Zhang, "High performance control of a three level IGBT inverter fed ac drive," Conf. Rec. of IEEE IAS Annual Meeting, 1995, pp. 22-28.

[14] G. Sinha, T. A. Lipo, "A four level rectifier-inverter system for drive applications," Conf. Rec. of IAS Annual Meeting, 1996, pp. 980-987.

[15]R. W. Menzies, P. Steimer, J. K. Steinke, "Five-level GTO inverters for large induction motor drives," IEEE Trans. Industry Applications, vol. 30, no. 4, July 1994, pp. 938-944. 